\title{
Synthesis of Well-Defined Poly( $N, N$-diethylacrylamide)s End-Functionalized with Methacrylamide Structure by Means of Anionic Polymerization
}

\author{
Motoyasu Kobayashi, ${ }^{\dagger}$ Mitsuhiro HiRata, and Makoto TaKeISHI \\ Department of Polymer Science and Engineering, Yamagata University, Yonezawa 992-8510, Japan
}

(Received October 28, 2003; Accepted January 6, 2004)

\begin{abstract}
A specially designed $N, N$-dialkylmethacrylamide having a benzoyl chloride moiety in the $N$-alkyl chain (T) was prepared as a terminator for anionic polymerization of $N, N$-diethylacrylamide (DEA) to synthesize an end-functionalized polymer. Living poly(DEA) with narrow molecular weight distribution, which was produced by means of anionic polymerization of DEA with $\mathrm{Ph}_{2} \mathrm{CHK}$ in the presence of diethylzinc at $0{ }^{\circ} \mathrm{C}$, reacted with $\mathrm{T}$ to afford an end-functionalized poly(DEA) carrying a methacrylamide group at the chain end. The end-group functionality of the polymer obtained was estimated to be up to $98 \%$ by ${ }^{1} \mathrm{H}$ and ${ }^{13} \mathrm{CNMR}$ and MALDI-TOF-MS analysis. However, the sufficient functionalization was not achieved because of side reactions when the living polymer generated with an organolithium initiator was used. Although the end-functionalized poly(DEA) is a macromonomer, neither polymerization nor oligomerization took place with any anionic initiator, but only a monoaddition product between them was obtained because $\mathrm{N}, \mathrm{N}$-disubstituted methacylamides are difficult to be polymerized. The end-functionalized poly(DEA) reacted with $\mathrm{Ph}_{2} \mathrm{CHK}$ equivalently to afford a well-defined anionic macroinitiator that initiates another anionic polymerization of DEA to yield a postpolymer consisting of two poly(DEA) blocks.

KEY WORDS End-Functionalized Polymer / Anionic Polymerization / $N, N$-Diethylacrylamide / $N, N$-Dialkylmethacrylamide / Diethylzinc /
\end{abstract}

It is well known that the addition reaction of 1,1-diphenylethylene (DPE) derivatives with anionic initiators, or anionic living polymers, proceeds quantitatively to form monoaddition product. ${ }^{1}$ Neither polymerization nor even oligomerization of them, however, takes place under usual conditions, presumably because of the steric hindrance of diphenylalkyl groups. ${ }^{2,3}$ Propagating 1,1-diphenylalkyl-type anions generated here are not terminated but still active for suitable initiation of polar vinyl monomers, ${ }^{4}$ and for diverse nucleophilic substitutions. Consequently, DPE derivatives have often been employed as useful agents for chain-end functionalization of anionic living polymers and preparation of star-branched polymers with well-defined structures. ${ }^{5,6}$ However, DPE cannot be used for preparation of star polymers, every arm of which consists of methacrylate segments, because it does not react with the enolate living end of poly(methacrylate). Therefore, the novel vinyl monomer instead of DPE is necessary to form an another poly(methacrylate) arm.

We focussed on a $N, N$-disubstituted methacrylamide that has properties similar to DPE. Hogen-Esch and his co-workers described that the reaction of $\mathrm{N}, \mathrm{N}$ dimethylmethacrylamide (DMMA) with triphenylmethyl cesium in THF at $-78^{\circ} \mathrm{C}$ produced no polymer, although the initiation was expected to occur. ${ }^{7}$
They assumed that the low polymerizability of DMMA was caused by the twisted conformation between carbonyl and vinyl groups that reduces the conjugation of the $\pi$ bonds, leading to less stable amide enolate intermediate upon monomer addition. ${ }^{7,8}$ Okamoto et al. found that exceptional anionic polymerization of $N$-methacyloylaziridine proceeded with a phenyl Grignard reagent or BuLi in toluene. ${ }^{9}$ However, they also reported that no polymer was obtained by anionic polymerization of DMMA and $N, N$-diphenylmethacrylamide with $\mathrm{BuLi}$ in toluene and THF at $-78^{\circ} \mathrm{C}$. Although oligomers are expected to be generated in the case of DMMA polymerization, methacrylamide derivatives with steric $N$-alkyl groups react with anionic initiators in a monoaddition manner without any oligomer formation.

To achieve the precise synthesis of star-branched polymers, a well-defined polymer end-functionalized with methacrylamide derivatives is necessary. Hogen-Esch and his co-workers successfully synthesized a poly $(N, N$-dimethylacrylamide $)$ end-functionalized with perfluoroalkyl groups by the reaction of a cesium salt of anionic living poly $(N, N$-dimethylacrylamide) with perfluoroocatanoyl chloride. ${ }^{10} \mathrm{We}$ previously reported that the anionic polymerization of $\mathrm{N}, \mathrm{N}$-dialkylacrylamide with $\mathrm{Ph}_{2} \mathrm{CHK}$ in the presence of weak Lewis acid, such as diethylzinc ${ }^{11}$ and triethyl-

${ }^{\dagger}$ To whom correspondence should be addressed (FAX: +81-238-26-3088, E-mail: motokoba@yz.yamagata-u.ac.jp). 
borane, ${ }^{12}$ in THF at $0{ }^{\circ} \mathrm{C}$ produced the polymers with predictable molecular weights and narrow molecular weight distributions in a quantitative yield. This combination of a Lewis acid and an anionic initiator seems to be an excellent method to control the molecular weights and stereoregularities of various $\mathrm{N}, \mathrm{N}$-dialkylacrylamide polymers, probably because the anionic propagating end coordinate with the Lewis acid to lower the reactivity to suppress the side reactions. However, the reactivity of the amide enolate coordinated with the Lewis acid has not been investigated in detail.

We wish to report in the present paper the reactivity of living anionic polymers with electrophillic reagents such as acid chloride and alkyl halide for the preparation of end-functionalized polymers. As a result, welldefined poly(DEA)s having a methacrylamide group at the chain-end were synthesized by the termination reaction of living anionic polymers with specially designed benzoyl chloride derivatives. In addition, obtained end-functionalized poly(DEA) was further reacted with an anionic initiator to produce a macroinitiator.

\section{EXPERIMENTAL}

\section{Materials}

THF was refluxed over sodium wire, distilled over $\mathrm{LiAlH}_{4}$, and then distilled from sodium naphthalene solution on a vacuum line. $\mathrm{Et}_{2} \mathrm{Zn}$ was purchased from KANTO KAGAKU Co. and was used as a THF solution. 1,1-Bis[(4'-trimethylsilyl)phenyl]ethylene $\left(\mathrm{TMS}_{2} \mathrm{DPE}\right)^{13}$ was dried and distilled over $\mathrm{CaH}_{2}$. The synthesis and purification procedures of DEA have been described in our previous publication. ${ }^{11}$ Commercially available $s$-BuLi was used without further purification. $\mathrm{Ph}_{2} \mathrm{CHK}$ was prepared by the reaction of diphenylmethane and potassium naphthalene in THF at room temperature, and the concentration was determined by colorimetric titration with 1-octanol in a sealed tube in vacuo. ${ }^{14}$

\section{Methyl 4-methylbenzoate (1)}

In a round-bottom flask, $20 \mathrm{~g}$ of $p$-toluic acid $(147 \mathrm{mmol})$ was kept in $40 \mathrm{~mL}$ of refluxed methanol in the presence of conc. $\mathrm{H}_{2} \mathrm{SO}_{4}(2.2 \mathrm{~mL})$ for $2.5 \mathrm{~h}$. After the methanol was evaporated under reduced pressure, $\mathrm{Et}_{2} \mathrm{O}$ was added to the reaction mixture for washing it twice with saturated aqueous $\mathrm{NaHCO}_{3}$ solution and successively with water. The solution in $\mathrm{Et}_{2} \mathrm{O}$ was dried over anhydrous magnesium sulfate $\left(\mathrm{MgSO}_{4}\right)$, and filtered off. The product was purified by fractional distillation at $84-86^{\circ} \mathrm{C}(8 \mathrm{mmHg})$ to give $14.9 \mathrm{~g}(99.0 \mathrm{mmol}, 67 \%)$ of $\mathbf{1}$ as a colorless liquid.

\section{Methyl 4-(bromomethyl)benzoate $(2)^{15}$}

In a three-necked flask, a mixture of $\mathbf{1}(17.33 \mathrm{~g}, 115$ mmol), $N$-bromosuccinimide $(20.88 \mathrm{~g}, 116 \mathrm{mmol})$, and dibenzoyl peroxide $(0.40 \mathrm{~g}, 1.65 \mathrm{mmol})$ in $80 \mathrm{~mL}$ of carbon tetrachloride was refluxed for $2 \mathrm{~h}$. The reaction mixture was allowed to cool to room temperature, and solid impurities were filtered off. After removal of carbon tetrachloride in vacuo from the filtrate, $\mathrm{Et}_{2} \mathrm{O}$ was added to the residue. The solution in $\mathrm{Et}_{2} \mathrm{O}$ was washed three times with saturated aqueous $\mathrm{NaHCO}_{3}$ solution, and dried over anhydrous $\mathrm{MgSO}_{4}$. After the drying agent was removed by filtration and $\mathrm{Et}_{2} \mathrm{O}$ was evaporated, the product was purified by distillation and silica-gel column chromatography with hexane/ethyl acetate $(9 / 1, \mathrm{v} / \mathrm{v})$ to afford $\mathbf{2}$ as a colorless oil in $67 \%$ yield. bp. $95^{\circ} \mathrm{C} / 2 \mathrm{mmHg} .{ }^{1} \mathrm{H} N M R$ $\left(\mathrm{CDCl}_{3}\right) \delta 3.92(\mathrm{~s}, 3 \mathrm{H}), 4.50(\mathrm{~s}, 2 \mathrm{H}), 7.47(\mathrm{~d}, 2 \mathrm{H})$, $8.02(\mathrm{~d}, 2 \mathrm{H})$.

\section{Methyl 4-(N-phenylaminomethyl)benzoate (3)}

To the refluxed mixture of aniline $(6.42 \mathrm{~g}$, $68.9 \mathrm{mmol})$ with $\mathrm{NaHCO}_{3}(1.91 \mathrm{~g}, 22.7 \mathrm{mmol})$ in $50 \mathrm{~mL}$ of water, $2(4.77 \mathrm{~g}, 22.2 \mathrm{mmol})$ was slowly added over a period of $15 \mathrm{~min}$. After the reaction under reflux with vigorous stirring for $2 \mathrm{~h}$, the mixture was extracted with $\mathrm{Et}_{2} \mathrm{O}$, and then dried over anhydrous $\mathrm{MgSO}_{4}$. The excess of aniline was removed by distillation under reduced pressure, and the residue was purified by recrystallization from $\mathrm{Et}_{2} \mathrm{O}$ /petroleum ether $(2 / 8, \mathrm{v} / \mathrm{v})$ yielding $2.99 \mathrm{~g}$ of $\mathbf{3}(12.4 \mathrm{mmol}, 56 \%)$ as a colorless solid. ${ }^{1} \mathrm{H}$ NMR $\left(\mathrm{CDCl}_{3}\right) \delta 3.91(\mathrm{~s}, 3 \mathrm{H})$, $4.41(\mathrm{~s}, 2 \mathrm{H}), 6.61(\mathrm{~d}, 2 \mathrm{H}), 6.73(\mathrm{t}, 1 \mathrm{H}), 7.17(\mathrm{t}, 2 \mathrm{H})$, $7.45(\mathrm{~d}, 2 \mathrm{H}), 8.01(\mathrm{~d}, 2 \mathrm{H}) .{ }^{13} \mathrm{C} \mathrm{NMR}\left(\mathrm{CDCl}_{3}\right) \delta 48.0$ $\left(\mathrm{CH}_{2}\right), 62.1\left(\mathrm{OCH}_{3}\right), 113.0,118.9,129.3,148.0(\mathrm{~N}-$ $\mathrm{Ar}), 127.3,129.5,130.1,145.1(\mathrm{Ar}), 167.2(\mathrm{C}=\mathrm{O})$.

\section{$\mathrm{N}$-(4-methoxycarbonylphenyl)methyl-N-phenylmetha- crylamide (4)}

To a stirred solution of $\mathbf{3}(0.97 \mathrm{~g}, 4.02 \mathrm{mmol})$ and triethylamine $(0.32 \mathrm{~g}, 3.16 \mathrm{mmol})$ in $20 \mathrm{~mL}$ of dry $\mathrm{Et}_{2} \mathrm{O}$ under nitrogen, methacryloyl chloride $(0.41 \mathrm{~g}$, $3.92 \mathrm{mmol}$ ) in $5 \mathrm{~mL}$ of dry $\mathrm{Et}_{2} \mathrm{O}$ was added dropwise at $0{ }^{\circ} \mathrm{C}$. The reaction mixture was stirred at $0{ }^{\circ} \mathrm{C}$ for $5 \mathrm{~h}$. The resulting solution was washed twice with a sat. aq. $\mathrm{NaHCO}_{3}$ solution and successively with water, and then dried over anhydrous $\mathrm{MgSO}_{4}$. After removal of the drying agent and evaporation of the solvent, the residue was purified by silica-gel column chromatography using hexane/ethyl acetate $(8 / 2-6 / 4, v / v)$ to afford $0.79 \mathrm{~g}$ of $\mathbf{3}(2.55 \mathrm{mmol} .65 \%)$ as a colorless solid. ${ }^{1} \mathrm{H}$ NMR $\left(\mathrm{CDCl}_{3}\right) \delta 1.75(\mathrm{~s}, 3 \mathrm{H}), 3.88(\mathrm{~s}, 3 \mathrm{H}), 5.00$ (s, 2H), 5.05 (d, 2H), 6.97 (d, 2H), $7.23(\mathrm{t}, 2 \mathrm{H}), 7.26$ $(\mathrm{t}, 1 \mathrm{H}), 7.31(\mathrm{~d}, 2 \mathrm{H}), 7.95(\mathrm{~d}, 2 \mathrm{H}) .{ }^{13} \mathrm{C} \mathrm{NMR}\left(\mathrm{CDCl}_{3}\right)$ $\delta 20.4\left(\alpha-\mathrm{CH}_{3}\right), 52.2\left(\mathrm{OCH}_{3}\right), 53.0\left(\mathrm{NCH}_{2}\right), 120.0$ $\left(\mathrm{CH}_{2}=\right), 127.3,127.4,128.4,129.2,129.3,129.9$ 


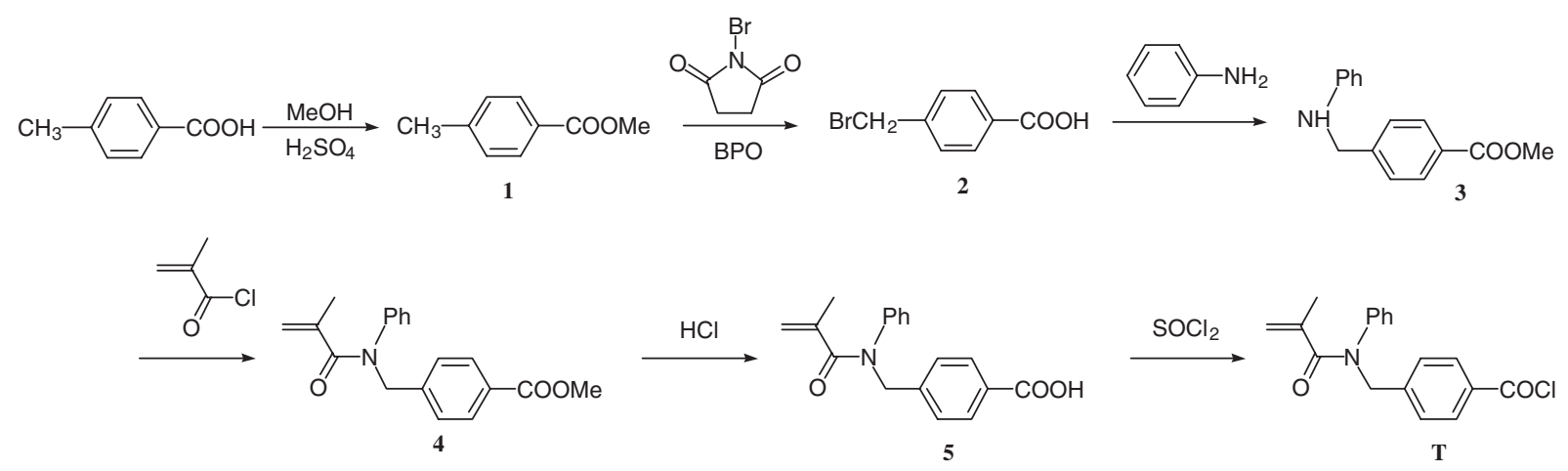

Scheme 1.

(Ar), $140.5(\alpha-\mathrm{C}), 142.8,143.0(\mathrm{Ar}), 167.0$ (ester $\mathrm{C}=\mathrm{O}$ ), 172.0 (amide $\mathrm{C}=\mathrm{O}$ ).

\section{4-(N-pheny-N-methacryloyl)aminomethylbenzoic Acid} (5)

In a round-bottom flask, $2.99 \mathrm{~g}$ of $4(9.66 \mathrm{mmol})$ was stirred with conc. $\mathrm{HCl}(20 \mathrm{~mL})$ vigorously at $85^{\circ} \mathrm{C}$ for $4 \mathrm{~h}$. The solution was concentrated using vacuum pump to remove hydrochloric acid, and then $\mathrm{Et}_{2} \mathrm{O}$ was added to the residue with stirring to rinse off impurities by successive decantation of the supernatant. The residue was dried under reduced pressure to give $1.21 \mathrm{~g}$ of colorless solid, pure $\mathbf{5},(4.10 \mathrm{mmol}$, $42 \%)$ was obtained. ${ }^{1} \mathrm{HNMR}\left(\mathrm{CDCl}_{3}\right) \delta 1.76(\mathrm{~s}$, $3 \mathrm{H}), 5.02(\mathrm{~s}, 2 \mathrm{H}), 5.05(\mathrm{~d}, 1 \mathrm{H}), 6.94(\mathrm{~d}, 2 \mathrm{H}), 7.23(\mathrm{t}$, 2H), $7.26(\mathrm{t}, 1 \mathrm{H}), 7.32(\mathrm{~d}, 2 \mathrm{H}), 7.99(\mathrm{~d}, 2 \mathrm{H}) .{ }^{13} \mathrm{CNMR}$ $\left(\mathrm{CDCl}_{3}\right) \delta 20.4\left(\alpha-\mathrm{CH}_{3}\right), 53.3\left(\mathrm{NCH}_{2}\right), 119.9\left(\mathrm{CH}_{2}=\right)$, 127.4, 127.4, 128.5, 128.6, 129.4, 130.5 (Ar), 140.5 $(\alpha-\mathrm{C}), 143.2,143.7$ (Ar), 168.0 (carboxylic acid $\mathrm{C}=\mathrm{O}$ ), 171.2 (amide $\mathrm{C}=\mathrm{O}$ ).

\section{4-(N-pheny-N-methacryloyl)aminomethylbenzoyl Chloride $(\boldsymbol{T})$}

Into a round-bottom flask equipped with an outlet for evacuation and with a break-seal, $0.51 \mathrm{~g}$ of $\mathbf{5}$ $(1.73 \mathrm{mmol})$ was introduced and the content was dried under a high vacuum condition for $2 \mathrm{~h}$. The flask was purged with argon, freshly distilled thionyl chloride $(0.68 \mathrm{~g}, 5.72 \mathrm{mmol})$ was slowly added to the content, and then the solution was stirred at room temperature for $90 \mathrm{~min}$. After the reaction, excess thionyl chloride was removed in vacuo, and a dry hexane/ $\mathrm{Et}_{2} \mathrm{O}(9 / 1$, $\mathrm{v} / \mathrm{v}$ ) solution was added to the residue. The resulting suspension was stirred vigorously to extract the impurities from the crude product. Suction of the supernatant of the suspension and the repeated extraction with the hexane $/ \mathrm{Et}_{2} \mathrm{O}$ solution yielded $0.35 \mathrm{~g}$ of colorless solid $\mathbf{T}(1.12 \mathrm{mmol}, 65 \%)$, and its structure and purity were confirmed by NMR and IR. ${ }^{1} \mathrm{H}$ NMR $\left(\mathrm{CDCl}_{3}\right) \delta 1.79(\mathrm{~s}, 3 \mathrm{H}), 5.06(\mathrm{~s}, 2 \mathrm{H}), 5.07(\mathrm{~d}, 1 \mathrm{H})$, $7.01(\mathrm{~d}, 2 \mathrm{H}), 7.26(\mathrm{t}, 2 \mathrm{H}), 7.30(\mathrm{t}, 1 \mathrm{H}), 8.04(\mathrm{~d}, 2 \mathrm{H})$. ${ }^{13} \mathrm{CNMR}\left(\mathrm{CDCl}_{3}\right) \delta 20.2\left(\alpha-\mathrm{CH}_{3}\right), 52.9\left(\mathrm{NCH}_{2}\right)$,
$120.3\left(\mathrm{CH}_{2}=\right), 127.2,127.5,128.8,129.4,131.8$, $132.3(\mathrm{Ar}), 140.3(\alpha-\mathrm{C}), 143.0,145.8(\mathrm{Ar}), 168.1$ (COCl), 172.1 (amide $\mathrm{C}=\mathrm{O}) . \mathrm{IR}\left(\mathrm{KBr}, \mathrm{cm}^{-1}\right) 1650$ $(\mathrm{C}=\mathrm{O}$ of amide), $1743(\mathrm{C}=\mathrm{O}$ of acid chloride). The obtained $\mathbf{T}$ was sealed off under degassed condition in the flask and diluted with dry THF by a usual break-seal method. The series of reaction for the preparation of $\mathbf{T}$ are shown in Scheme 1.

\section{Initiators}

To a THF solution of $\mathrm{Ph}_{2} \mathrm{CHK}$ or to a heptane solution of $s$-BuLi, was added a slight molar excess of $\mathrm{TMS}_{2} \mathrm{DPE}$ in THF and the mixtures were kept at $-78^{\circ} \mathrm{C}$ for $20 \mathrm{~min}$ to give 1,1-bis[(4'-trimethylsilyl)phenyl]-3,3-diphenylpropylpotassium $\left(\mathrm{R}^{1} \mathrm{~K}\right)$ and 1,1bis[(4'-trimethylsilyl)phenyl]-3-methylpentyllithium $\left(\mathrm{R}^{2} \mathrm{Li}\right)$.

\section{Polymerization and End-fucntionalization of Poly- mers}

The polymerization was typically performed under vacuum conditions in a glass apparatus equipped with breakseals as follows: An excess amount of $\mathrm{Et}_{2} \mathrm{Zn}$ was introduced into a initiator solution in the apparatus, and the solution was kept at $-78^{\circ} \mathrm{C}$ for $10 \mathrm{~min}$, and then DEA dissolved in THF was added to the initiating system with vigorous stirring at -78 or $0^{\circ} \mathrm{C}$ (Table I). On addition of DEA, the characteristic red color of the initiator solution disappeared immediately and turned pale yellow. To the resulting living polymer solution, a THF solution of $\mathbf{T}$ obtained above was added directly at $0{ }^{\circ} \mathrm{C}$ to produce the end-functionalized poly(DEA) (Scheme 3). After the successive reactions the solution was concentrated by evaporation and poured into a large amount of hexane to precipitate the polymer. The separated crude polymer was dissolved again in THF and the precipitated zinc impurity was filtered out. The polymer was further purified by freeze-drying from benzene.

\section{Measurements}

Molecular weights and molecular weight distribu- 
Table I. Synthesis of end-functionalized poly(DEA) ${ }^{\mathrm{a}}$

\begin{tabular}{|c|c|c|c|c|c|c|c|c|c|c|c|c|c|c|}
\hline \multirow{2}{*}{ run } & \multirow{2}{*}{\multicolumn{2}{|c|}{$\begin{array}{c}\text { Initiator }^{\mathrm{b}} \\
\text { mmol }\end{array}$}} & \multirow{2}{*}{$\begin{array}{l}\mathrm{Et}_{2} \mathrm{Zn} \\
\mathrm{mmol}\end{array}$} & \multirow{2}{*}{$\begin{array}{l}\text { DEA } \\
\text { mmol }\end{array}$} & \multicolumn{2}{|c|}{ Polymerization } & \multirow{2}{*}{$\begin{array}{c}\mathbf{T} \\
(\mathrm{mmol})\end{array}$} & \multicolumn{2}{|c|}{ Termination } & \multirow{2}{*}{$\begin{array}{l}\text { Yield } \\
(\%)\end{array}$} & \multicolumn{2}{|c|}{$M_{\mathrm{n}} \times 10^{-3}$} & \multirow{2}{*}{\multicolumn{2}{|c|}{$\begin{array}{c}\text { e }^{\text {Functionality }^{\mathrm{f}}} \\
(\%)\end{array}$}} \\
\hline & & & & & temp. $\left({ }^{\circ} \mathrm{C}\right)$ & time $(\min )$ & & temp. $\left({ }^{\circ} \mathrm{C}\right)$ & time $(\min )$ & & calc. $^{\mathrm{c}}$ & obs. $^{\text {d }}$ & & \\
\hline 1 & $\mathrm{R}^{1} \mathrm{~K}$ & 0.247 & 3.47 & 6.31 & 0 & 1 & 0.308 & 0 & 60 & 96 & 3.9 & 4.2 & 1.12 & 98 \\
\hline 2 & $\mathrm{Ph}_{2} \mathrm{CHK}$ & 0.274 & 4.38 & 8.01 & 0 & 1 & 0.361 & 0 & 60 & 100 & 4.2 & 5.0 & 1.10 & 95 \\
\hline 3 & $\mathrm{R}^{2} \mathrm{Li}$ & 0.239 & 3.60 & 6.81 & -78 & 10 & 0.269 & 0 & 60 & 97 & 4.2 & 5.1 & 1.15 & 77 \\
\hline 4 & $\mathrm{R}^{2} \mathrm{Li}$ & 0.292 & 4.14 & 6.34 & -78 & 8 & 0.358 & 0 & 1 & 100 & 3.4 & 4.5 & 1.16 & 80 \\
\hline 5 & $\mathrm{R}^{2} \mathrm{Li}$ & 0.418 & 6.01 & 7.28 & -78 & 5 & 0.434 & -78 & 60 & 100 & 2.9 & 4.0 & 1.63 & 74 \\
\hline
\end{tabular}

${ }^{\mathrm{a}}$ The reactions were carried out in THF $(c a .30 \mathrm{~mL}) .{ }^{\mathrm{b}} \mathrm{R}^{1} \mathrm{~K}$ and $\mathrm{R}^{2} \mathrm{Li}$ are shown in Scheme $2 .{ }^{\mathrm{c}} M_{\mathrm{n}}(\mathrm{calc})=$. $(\mathrm{MW}$ of DEA $) \times$ Yield $/ 100 \times[$ monomer $] /[$ initiator $]+(\mathrm{MW}$ of initiator $)+\left(\mathrm{MW}\right.$ of T1). ${ }^{\mathrm{d}}$ Determined by ${ }^{1} \mathrm{H}$ NMR based on area integration of the main chain and initiator residue peaks. ${ }^{\mathrm{e}}$ Measured by SEC using polystyrene standards in THF. ${ }^{\mathrm{f}}$ Determined by ${ }^{1} \mathrm{H}$ NMR.

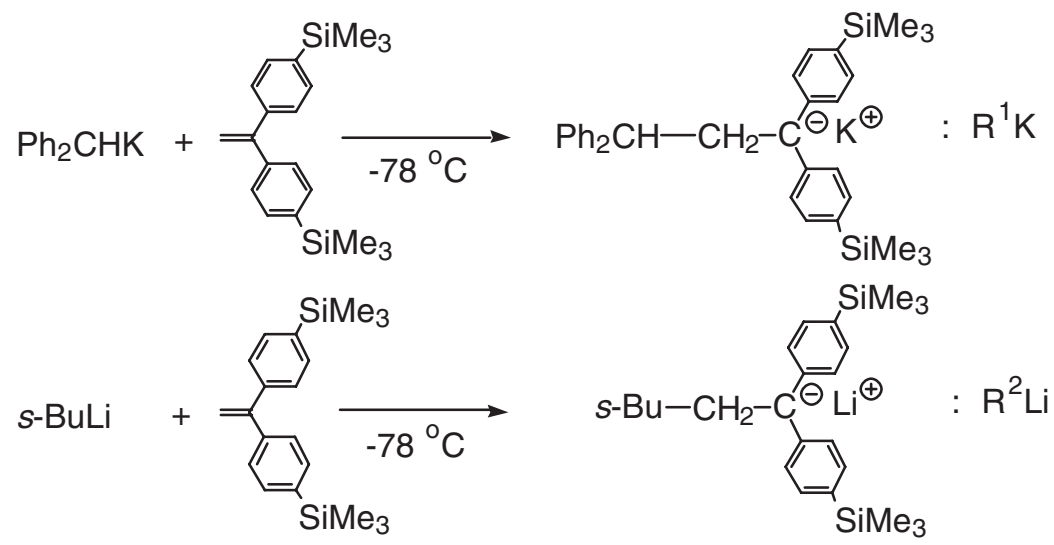

Scheme 2.

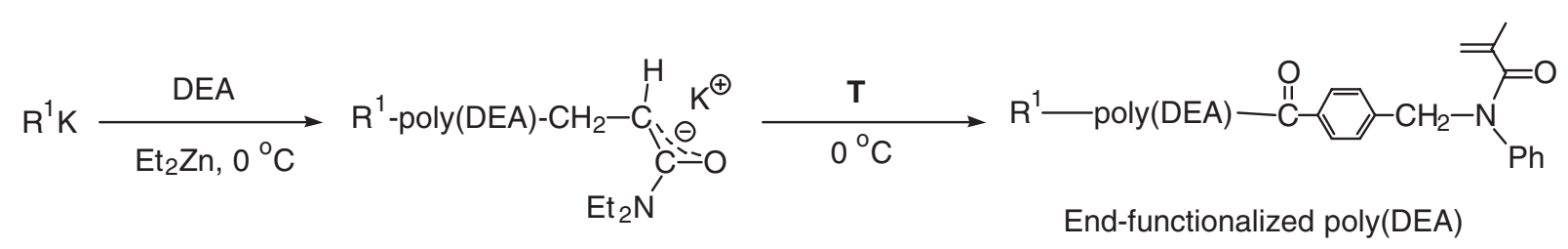

Scheme 3.

tions of polymers were determined by SEC on a JASCO instrument equipped with a JASCO 830-RI reflective index detection and a UV-975 ultraviolet detector $(254 \mathrm{~nm})$ using THF as an eluent, which runs through directly connected three polystyrene gel columns (TOSOH G4000H $\mathrm{HR} \times 2$ and $\mathrm{G} 2500 \mathrm{H}_{\mathrm{HR}}$, flow rate $1.0 \mathrm{~mL} / \mathrm{min}$ ) at $40^{\circ} \mathrm{C}$. The $M_{\mathrm{n}}$ of the resulting polymer was also estimated based on the relative intensities of the proton NMR signals of the main and side chains of the polymer and trimethylsilyl proton signal $(0.1-0.2 \mathrm{ppm})$ of the initiator fragment attached to the polymer chain end. The NMR spectra were recorded with a VARIAN INOVA-500 $\quad\left({ }^{1} \mathrm{H}\right.$ $500.16 \mathrm{MHz})$ and a JEOL EX-270 $\left({ }^{1} \mathrm{H} 270.11 \mathrm{MHz}\right)$ in $\mathrm{CDCl}_{3}$ at $50^{\circ} \mathrm{C}$. The chemical shifts in ppm were referenced to tetramethylsilane $(\delta 0)$ internal standard for ${ }^{1} \mathrm{HNMR}$, and $\mathrm{CDCl}_{3}\left(\delta\right.$ 77.1) for ${ }^{13} \mathrm{CNMR}$.

Matrix-assisted laser desorption/ionization time-offlight mass spectrometry (MALDI-TOF-MS) was per- formed on a PerSeptive Bio Systems Voyager DEPro in positive linear mode at $25 \mathrm{kV}$ ion acceleration with a $337 \mathrm{~nm}$ nitrogen laser. Trans-3-indoleacrylic acid (IAA) was used as the matrix. Polymer, IAA, and sodium trifluoroacetate (NaTFA) were dissolved in THF at concentrations of $1.5,10$, and $10 \mathrm{mg} / \mathrm{mL}$, respectively. The MALDI sample was prepared by mixing $10 \mu \mathrm{L}$ of the polymer solution, $90 \mu \mathrm{L}$ of the IAA solution, and $10 \mu \mathrm{L}$ of the NaTFA solution, and a $5 \mu \mathrm{L}$ aliquot of the mixed solution was applied to a target and air dried.

\section{RESULTS AND DISCUSSION}

Anionic Polymerization of N,N-Dialkylmethacrylamide

It has been reported that $N, N$-dialkylmethacrylamides do not afford any polymer or even an oligomer by anionic polymerization, except for limited cases. ${ }^{9}$ 


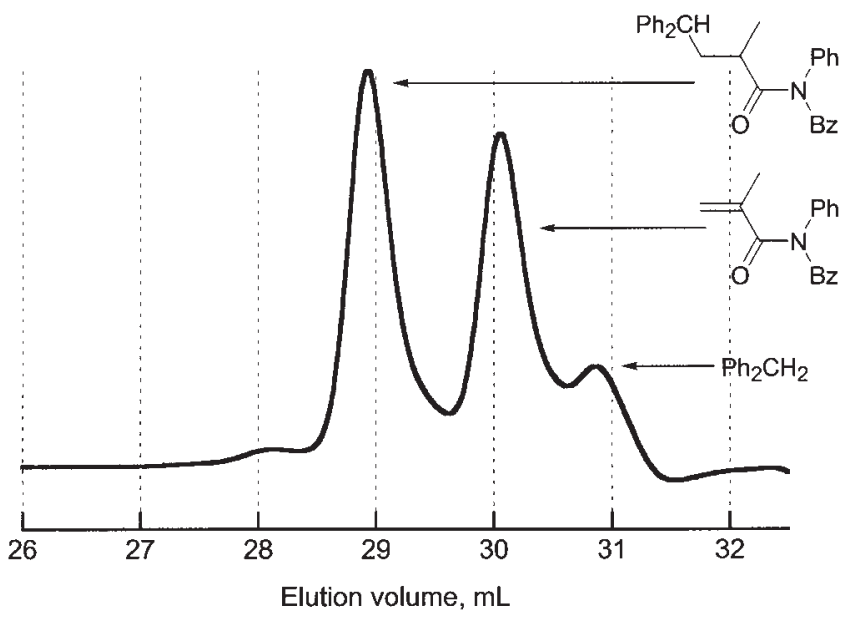

Figure 1. The SEC curve of a reaction mixture of $N$-benzyl$N$-phenylmethacrylamide with $\mathrm{Ph}_{2} \mathrm{CHK}$. $N$-benzyl- $N$-phenylmethacrylamide $2.51 \mathrm{mmol}, \mathrm{Ph}_{2} \mathrm{CHK} 0.465 \mathrm{mmol}$, THF $10 \mathrm{~mL}$, at $0^{\circ} \mathrm{C}, 1 \mathrm{~h}$.

To evaluate the polymerizability of $N, N$-dialkylmethacrylamides, $N$-benzyl- $N$-phenylmethacrylamide was examined whether it can be polymerized with $\mathrm{Ph}_{2} \mathrm{CHK}$ in THF at $0{ }^{\circ} \mathrm{C}$. The SEC profile of the reaction mixture of the monomer and the initiator after $1 \mathrm{~h}$ 's reaction showed three peaks at 29, 30, and 31 of elution volumes (Figure 1). The first fraction in the SEC curve was confirmed to be a monoaddition product of the monomer with $\mathrm{Ph}_{2} \mathrm{CHK}$ by ${ }^{1} \mathrm{H}$, ${ }^{13} \mathrm{CNMR}$, and ${ }^{1} \mathrm{H}-{ }^{1} \mathrm{H}$ COSY spectra, and EI mass analysis showed a molecular ion peak at $412(\mathrm{~m} / \mathrm{z})$ due to the addition product and the peaks at 342, 251, and 237 due to its fragments. The SEC peaks around 30 and 31 in elution volumes are due to the unreacted monomer and diphenylmetane, respectively. These observations indicate that neither oligomerization nor even dimerization of $N$-benzyl- $N$-phenylmethacrylamide took place under the conditions. Accordingly, $N$-benzyl- $N$-phenylmethacrylamide-type macromonomers seem difficult to undergo anionic polymerization.

\section{Synthesis of End-functionalized Polymers with Potas- sium Initiator}

The nucleophilicity of amide enolate anions depends on their countercation and reaction conditions. Woodbury and Rathke ${ }^{16}$ reported that the reaction of $\alpha$-lithio- $N, N$-dimethylacetamide with organic halides, carbonyl compounds, epoxides, and trialkylchlorosilanes to gave the corresponding products in high yields. Hogen-Esch and his co-workers ${ }^{17}$ prepared the end-functionalized poly( $N, N$-dimethylacrylamide) quantitatively by means of the anionic reaction of cesium salts of living polymers with perfluorooctanoyl chloride as a terminator in THF at $-78^{\circ} \mathrm{C}$. Furthermore, Müller et al. ${ }^{18}$ found that anionic polymeriza- tion of styrene with $\alpha$-potassio- $N, N$-dimethylpropionamide proceed in THF at room temperature, whereas the initiator efficiency was very low. These results suggest that the amide enolates, or the living pol$\mathrm{y}(N, N$-dialkylacrylamide) anions, react with various electrophiles. However, in our anionic polymerization system of DEA, $\mathrm{Et}_{2} \mathrm{Zn}$ as a weak Lewis acid coordinates with the amide enolate chain end to allow it to propagate by controlling its activity. The anionic living poly(DEA) generated with $\mathrm{Ph}_{2} \mathrm{CHK} / \mathrm{Et}_{2} \mathrm{Zn}$ in THF at $0{ }^{\circ} \mathrm{C}$ was found to be difficult to react with alkyl tosylates, alkyl iodides, esters, and epoxides, except for alkylcarboxylic halides. ${ }^{19}$ In this work, as shown in Scheme 1, a specially designed such a carboxylic chloride $(\mathbf{T})$ having a methacylamide moiety was synthesized as a terminator that reacts with anionic living polymers to give macromonomers.

Scheme 2 shows the formation of anionic initiators. The prepared $\mathrm{R}^{1} \mathrm{~K}$ initiated anionic polymerization of DEA producing living poly(DEA), and its successive reaction with terminator $\mathbf{T}$ yielded an end-functionalized poly(DEA) as shown in Scheme 3. Such poly(DEA)s obtained with $\mathrm{R}^{1} \mathrm{~K}$ or $\mathrm{R}^{2} \mathrm{Li}$ are presented in Table I. In the case with potassium initiators, after T was added to the living poly(DEA) solution, a dispersed colorless solid appeared in a few minutes because of $\mathrm{KCl}$ formation (run 1, run 2). After the addition of methanol to the reaction mixture, the formed polymers were isolated by precipitating them in hexane. The molecular weights of the end-functionalized polymers obtained were close to the predicted values, and MWD's were relatively narrow except for the case of run 5. SEC curves of run 1 and 2 revealed that the respective narrow peaks had no shoulder due to both higher and lower molecular weight products. ${ }^{1} \mathrm{HNMR}$ spectrum of the resulting macromonomer obtained in run 1 is shown in Figure 2. The signals around $4.9 \mathrm{ppm}$ are attributable to vinyl methylene and $\mathrm{N}$-benzyl methylene protons of $\mathbf{T}$ at the chain end. The end-functionality of $98 \%$ was estimated by ${ }^{1}$ HNMR: the area integration of the trimethylsilyl protons of the initiator at the chain head was compared with that of the vinyl methylene and the $\mathrm{N}$-benzyl methylene protons of $\mathbf{T}$ at the chain end. This ${ }^{1} \mathrm{HNMR}$ spectrum indicates that the propagating anionic chain end of living poly(DEA) reacted quantitatively with the acid chloride group of $\mathbf{T}$, and that the Michael addition to the vinyl group did not occur under the conditions. Thus, a N,N-disubstituted methacrylamide group was successfully introduced into poly(DEA) at the chain end.

Figure 3 exhibits the MALDI-TOF-MS spectrum of an end-functionalized poly(DEA) prepared by the reaction of $\mathbf{T}$ with a living poly(DEA) that was produced using $\mathrm{Ph}_{2} \mathrm{CHK}$ in the presence of $\mathrm{Et}_{2} \mathrm{Zn}$ at 


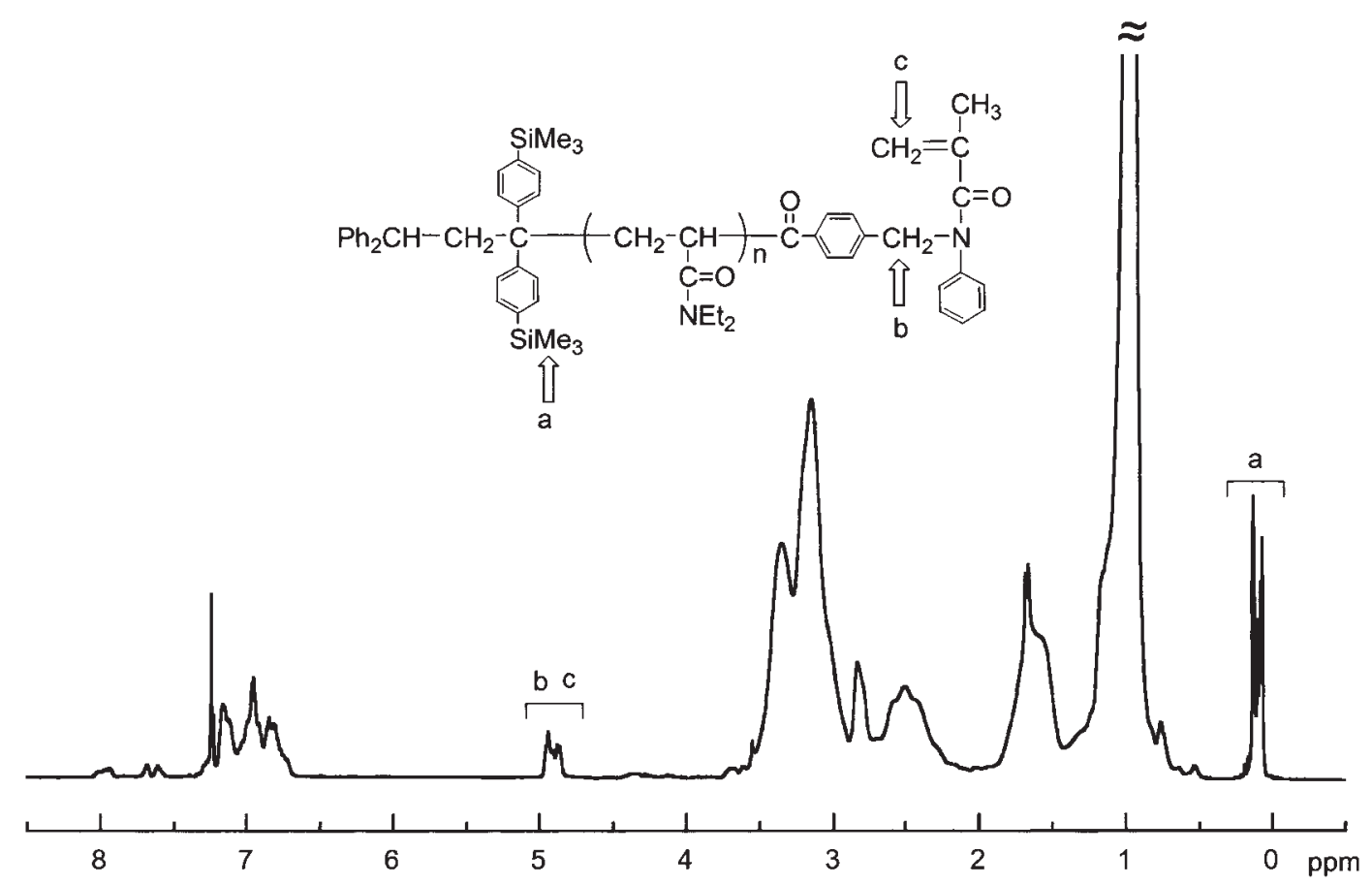

Figure 2. ${ }^{1}$ H NMR Spectrum of end-functionalized poly(DEA) prepared with living poly(DEA) and T (run 1 in Table I). See Scheme 3.<smiles>[3H]C(c1ccccc1)C(C)(C)CCC(NCC)C(C)(C)C(=O)c1ccc(CN(C(=O)C(=C)C)c2ccccc2)cc1</smiles>

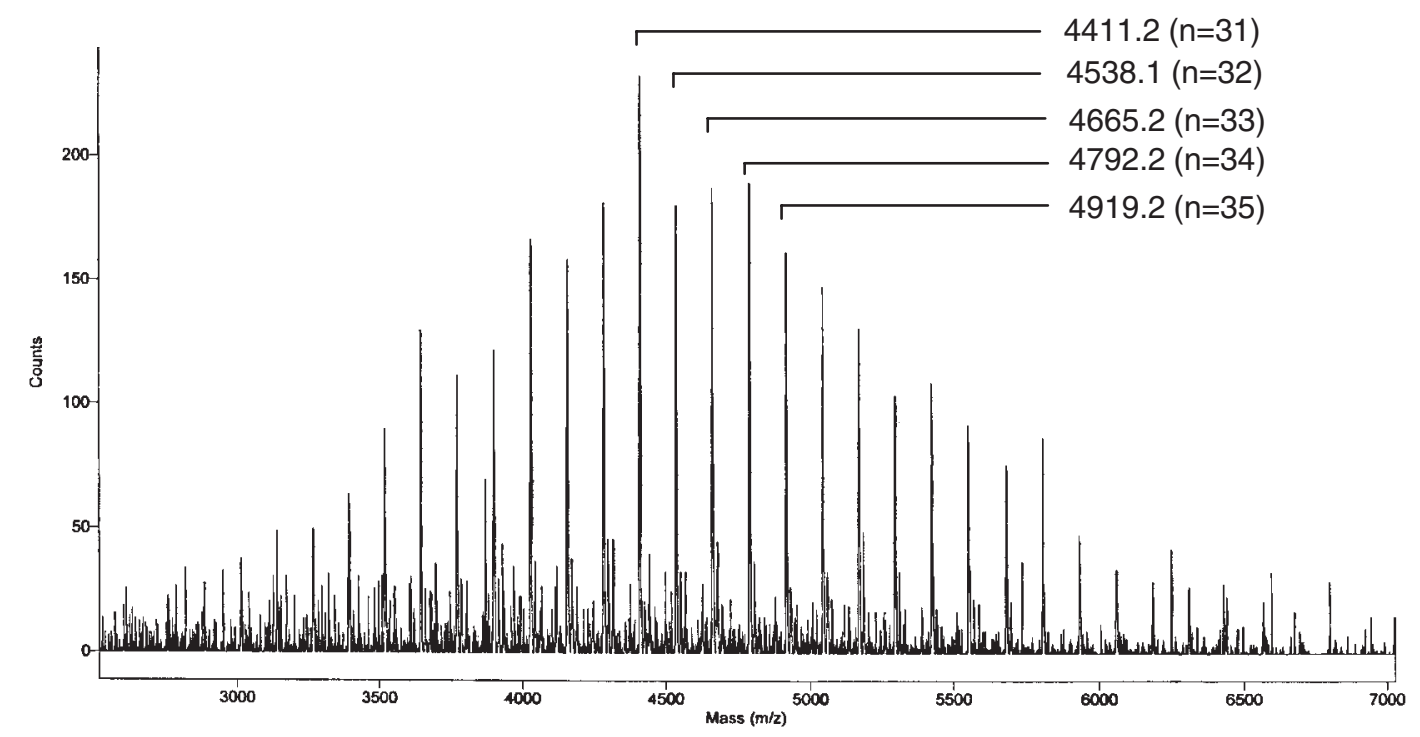

Figure 3. MALDI-TOF-MS of end-functionalized poly(DEA) obtained by the reaction of living poly(DEA) and T (run 2 in Table I).

$0{ }^{\circ} \mathrm{C}$ (run 2 in Table I). The peaks cover molecular weight regions of $\mathrm{m} / z 2000$ up to 7000 of the sodiated polymer. The series of observed masses $(\mathrm{m} / z=4411$, $4538,4665,4792,4919)$ are in good agreement with the value of the DEA unit (127.186 Da) multiplied by $n(n=31,32,33,34,35)$, the initiating $\mathrm{Ph}_{2} \mathrm{CH}$ group $(167.23 \mathrm{Da})$, the terminator residue without chlorine (278.0 Da), and $\mathrm{Na}(22.99 \mathrm{Da})$. Beside the main peak series, minor peaks appeared, which $(\mathrm{m} / z$ $=4427,4554,4681,4808,4935)$ are supposed to be potassium-ionized end-functionalized poly(DEA)s. The other minor peaks $(\mathrm{m} / \mathrm{z}=4444,4571,4698$, $4825,4952)$ seem to be end-functionalized poly(DEA)s that lost the $N$-phenylmethacrylamide group 


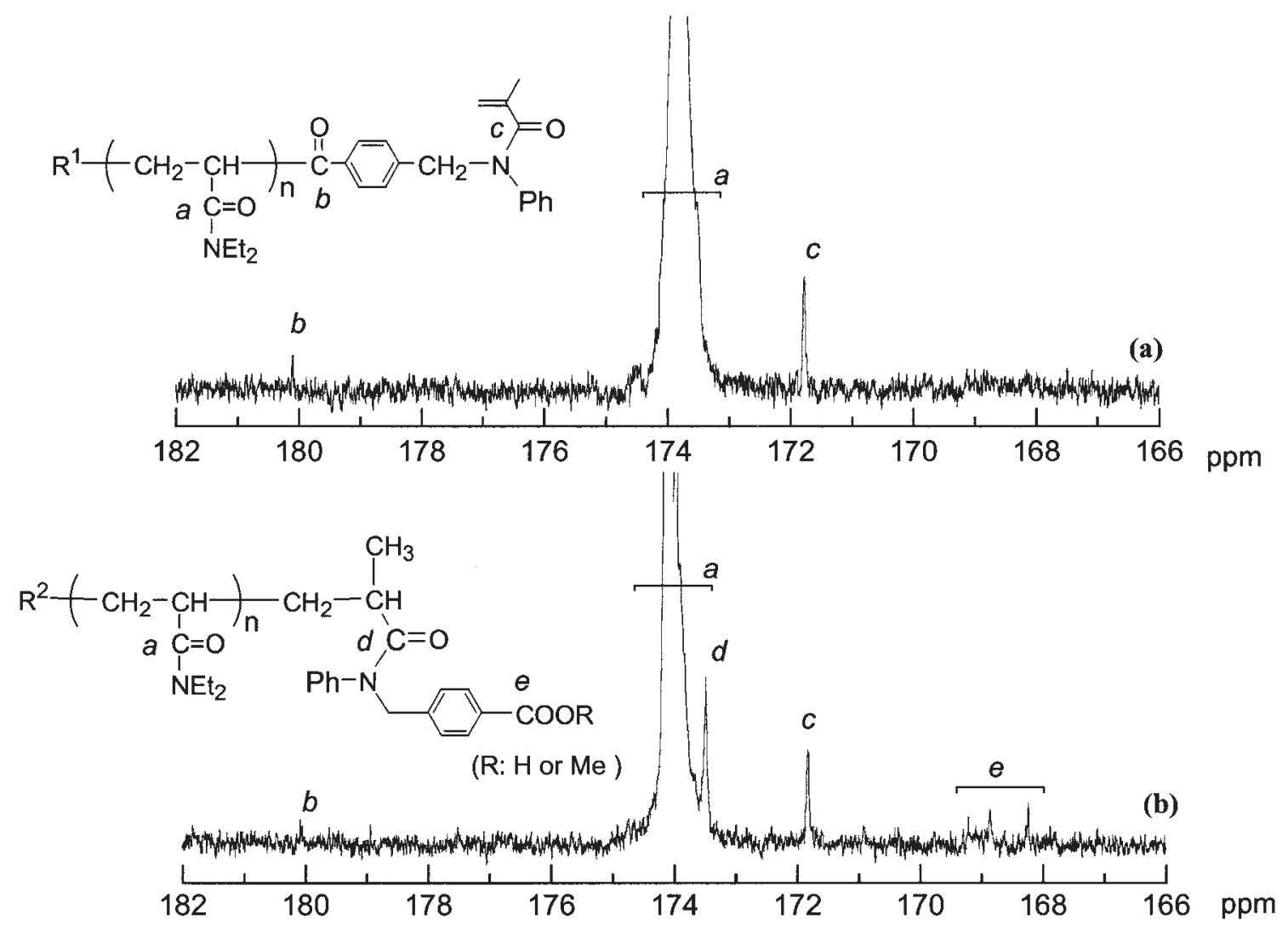

Figure 4. ${ }^{13} \mathrm{C}$ NMR spectra in the carbonyl region of resulting polymers obtained from living poly(DEA)s initiated with $\mathrm{R}^{1} \mathrm{~K}$ (run1 in Table I) (a), and $\mathrm{R}^{2} \mathrm{Li}$ (run 3 in Table I) (b).

during the MS measurment. Another peaks observed are supposed to be fragments of end functionalized poly(DEA)s or noises, because the peak intervals are not regular, and the intensities are very sensitive to the laser intensity and the accelerate voltage. It is likely that all peaks in the MS spectrum are due to the end-functionalized poly(DEA)s having $N$-benzyl- $N$ phenylmethacrylamide end. These results indicate that the nucleophilic reaction of the anionic living end with the acid chloride terminator, $\mathbf{T}$, occurred predominantly without side reactions to give the well-defined poly(DEA) having a functional methacrylamide structure at the chain end.

\section{Synthesis of End-functionalized Polymer with Orga- nolithium Initiator}

The functionalization reactions was also carried out by addition of $\mathbf{T}$ to the anionic living poly(DEA) prepared with organolithium initiator, $\mathrm{R}^{2} \mathrm{Li}$, in the presence of $\mathrm{Et}_{2} \mathrm{Zn}$ in THF at $-78^{\circ} \mathrm{C}$ (run 3 in Table I). The polymer was quantitatively obtained, but the end-functionality estimated by ${ }^{1} \mathrm{H}$ NMR analysis was $77 \%$. This value was rather smaller than that of the end-functionalized polymer obtained with a potassium initiator (run 1). The functionalities were not improved even when the polymerization time was shortened to eliminate successive side reactions (run 4) or the termination temperature was lowered to $-78^{\circ} \mathrm{C}$ (run 5). Figure 4 shows the ${ }^{13} \mathrm{C}$ NMR spectra of the resulting polymers obtained with living poly(DEA) initiated with $\mathrm{R}^{1} \mathrm{~K}$ or $\mathrm{R}^{2} \mathrm{Li}$ (run 1, run 3 ) in the carbonyl region. In the case of a functionalized poly(DEA) generated with $\mathrm{R}^{1} \mathrm{~K}$ as an initiator, the ${ }^{13} \mathrm{C}$ NMR signals at 171.8 and $180.2 \mathrm{ppm}$ due to the carbonyl carbons of methacryloyl and benzoyl groups were observed (Figure 4a). In addition to these signals, other signals also appeared at 168.2,168.8, 169.2, and $173.4 \mathrm{ppm}$ in the spectrum of the resulting polymer prepared with organolithium initiator (Figure $4 \mathrm{~b}$ ). The propagating amide enolate end seems to react with $\mathbf{T}$ not only at chlorocarbonyl group (termination), but also at the vinyl group (Michael addition). In the case of Michael addition, after isolation of the polymer, or during the reaction with methanol or atmospheric moisture, the carbonyl chloride residue was converted to methyl ester or carboxylic groups (Scheme 4a), as the signals in the region of 168-169 ppm imply. In addition, after the desired termination occurred yielding the endfunctionalized poly(DEA), another anionic living polymer might react with the poly(DEA) to afford additional polymers with larger molecular weights and with broad MWD's (Scheme 4b), as suggested above by run 5 in Table I. Since the poly(DEA) has an acidic $\alpha$-hydrogen between two carbonyls at the chain end, 


\section{Synthesis of End-Functionalized Poly( $N, N$-diethylacrylamide)s}

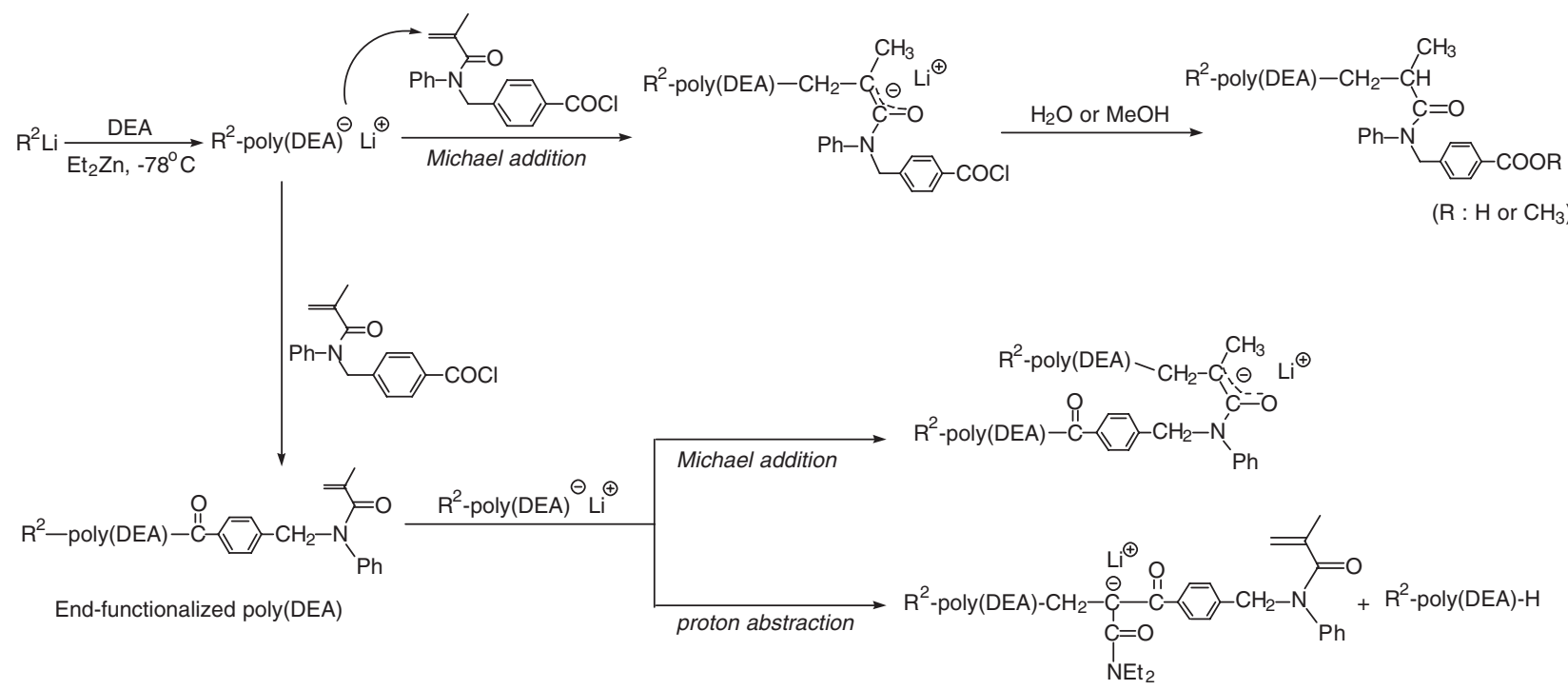

Scheme 4.

$\mathrm{Ph}_{2} \mathrm{CHK} \underset{\mathrm{Et}_{2} \mathrm{Zn}, 0^{\circ} \mathrm{C}}{\mathrm{DEA}} \mathrm{Ph}_{2} \mathrm{CH}$-poly $(\mathrm{DEA}) \Theta^{\ominus}{ }^{\oplus}$

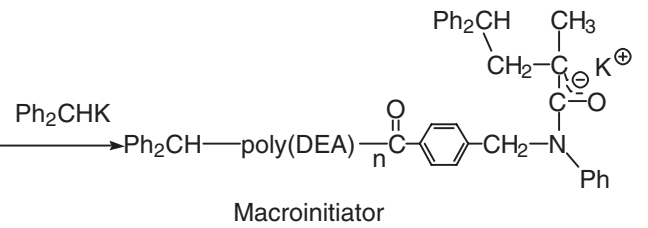

Macroinitiator

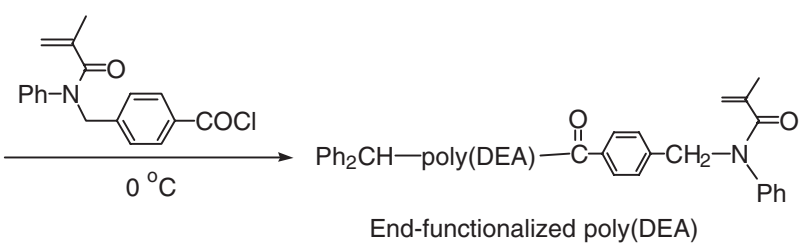

End-functionalized poly(DEA)

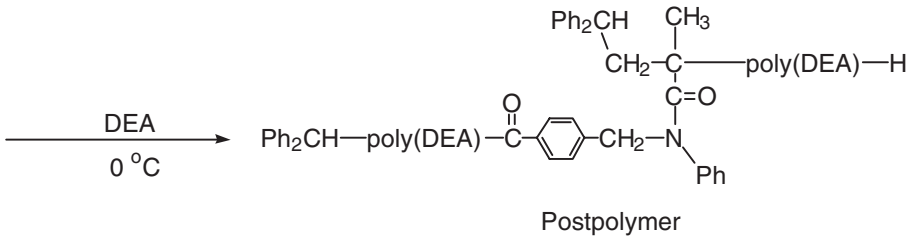

Scheme 5 .

the proton abstraction by another poly(DEA) anion would result in formation of polymers with low functionality (Scheme 4c). Hogen-Esch et al. further proposed that an analogous $\alpha$-proton abstraction led to $\beta$-elimination to form a $\alpha, \beta$-unsaturated carbonyl moiety, and the Michael addition of the living anionic chain end to the double bond afforded coupling products. ${ }^{10}$ In our experiments, the resulting polymers had narrow MWDs, except for that in run 5, and no coupled byproduct was detected on SEC curves. Therefore, the coupling reaction between polymers shown in Scheme $4 c$ is negligible in the reaction to prepare end-functionalized poly(DEA) using $\mathbf{T}$.

\section{Synthesis of Macroinitiator and Postpolymerization of} DEA

In general, macromonomers carrying some polymerizable functional groups at their chain ends can afford comb-like or graft copolymers by homopolymerization or copolymerization. The end-functionalized poly(DEA) prepared in this work also has a vinyl group at the polymer end; however, anionic polymerization of the vinyl group is difficult to proceed under usual conditions, because $N, N$-dialkylmethacrylamides are much less polymerizable. However, we found in the present study that DEA can be polymerized with $\mathrm{Ph}_{2} \mathrm{CHK}$, and the resultant end-functionalized poly(DEA) reacted with additional $\mathrm{Ph}_{2} \mathrm{CHK}$ to generate anionic macroinitiator that can also polymerize DEA to yield postpolymer (Scheme 5). The endfunctionalization was carried out by the termination reaction of $\mathbf{T}(0.429 \mathrm{mmol})$ with the living poly(DEA) obtained by anionic polymerization of DEA (7.20 mmol) with $\mathrm{Ph}_{2} \mathrm{CHK}(0.402 \mathrm{mmol})$ in the presence of $\mathrm{Et}_{2} \mathrm{Zn}(5.06 \mathrm{mmol})$ in $\mathrm{THF}$ at $0^{\circ} \mathrm{C}$, as described above. After the termination reaction, additional $\mathrm{Ph}_{2} \mathrm{CHK}(0.349 \mathrm{mmol})$ was added to the end-functionalized polymer in THF at $0{ }^{\circ} \mathrm{C}$, and the solution was allowed to stand for $10 \mathrm{~min}$. On addition of $\mathrm{Ph}_{2} \mathrm{CHK}$, the characteristic red color of the solution rapidly disappeared, probably because of the reaction with the $\mathrm{N}, \mathrm{N}$-disubstituted methacrylamide moiety at the chain end to form a propagating amide enolate end; interestingly a macroinitiator was generated $\left(M_{\mathrm{n}}=2900\right)$. A fresh feed of DEA $(13.4 \mathrm{mmol})$ to the resulting macroinitiator solution promoted post polymerization of the 


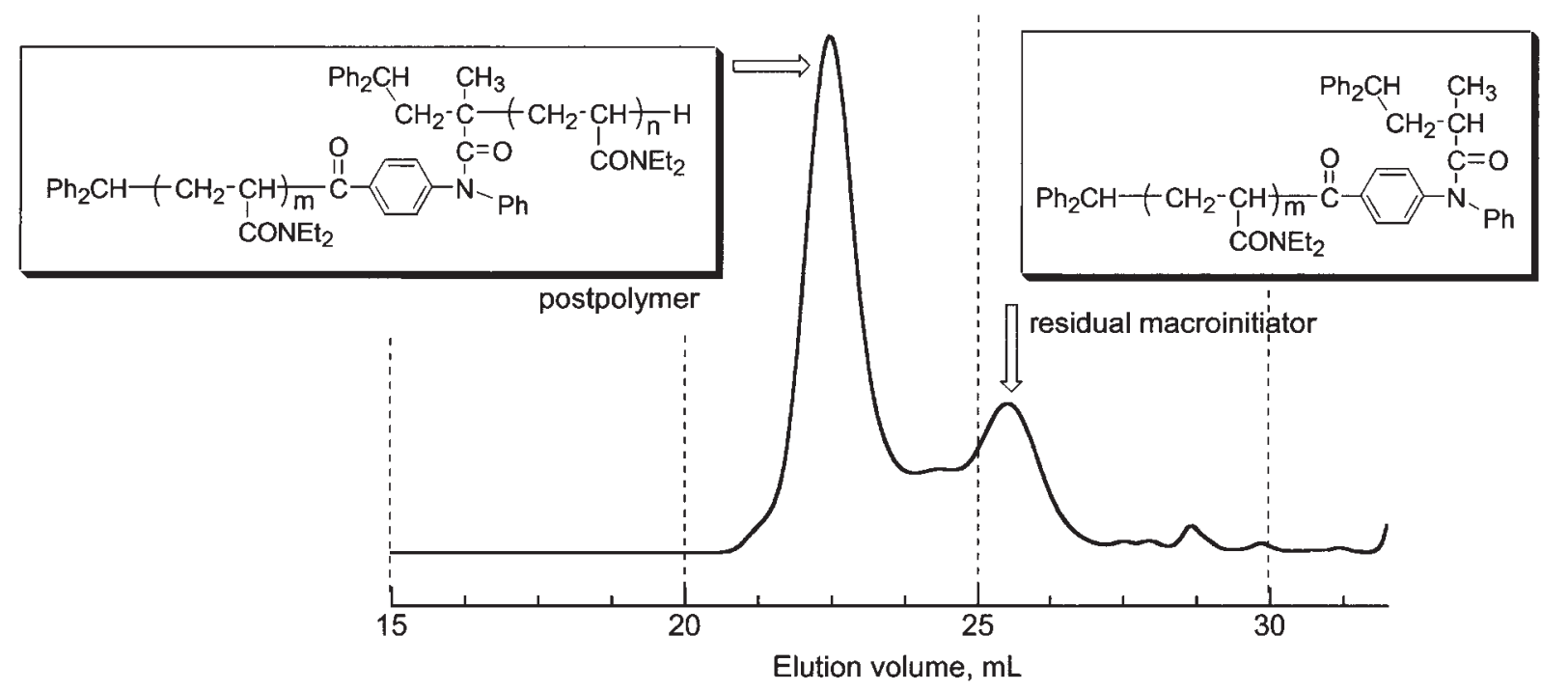

Figure 5. The SEC curve of the postpolymer using a macroinitiator with DEA in THF at $0{ }^{\circ} \mathrm{C}$ for $1 \mathrm{~h}$. See Scheme 5 .

monomer at $0{ }^{\circ} \mathrm{C}$, and $25 \mathrm{~min}$ later, methanol was added to terminate the polymerization yielding polymers with increased molecular weights. The SEC curve of the obtained polymer showed two peaks that are attributable to the postpolymer and the proton-terminated residual macroiniator, respectively (Figure 5). The molecular weight of the postpolymer $\left(M_{\mathrm{n}}=9900\right)$ determined by SEC was a little larger than the theoretical one $\left(M_{\mathrm{n}}=7900\right)$, probably because added $\mathrm{Ph}_{2}$ CHK was deactivated by a small excess of $\mathbf{T}$ for the termination and, consequently, the decrease in the number of the initiating chain end leaded to an increase in the molecular weight of the postpolymer. And the relatively narrow MWD is indicative of the absence of comb-like polymers that are to be formed by anionic polymerization of the end-functionalized poly(DEA) with $\mathrm{Ph}_{2} \mathrm{CHK}$.

The most noticeable aspect of this work is the successful anionic polymerization initiated by a macromolecular anionic species that was also synthesized by an anionic polymerization with a specific termination. This technique enables precision synthesis of specially designed block and star-branched copolymers that have various desired properties; for example, a star polymer with isotactic, syndiotactic, and heterotactic branches that is expected to have much interesting properties according to each branch. Further investigations on the synthesis of such a variety of polymers are in progress.

\section{CONCLUSIONS}

A living anionic polymer with a potassium counterion was prepared by anionic polymerization of DEA with $\mathrm{Ph}_{2} \mathrm{CHK}$ in the presence of $\mathrm{Et}_{2} \mathrm{Zn}$, and it was terminated with a specially prepared $N, N$-dialkylmethacrylamide derivative $(\mathbf{T})$ containing benzoyl chloride residue to afford a polymer with a methacrylamide group at the chain end. NMR, SEC, and MALDITOF-MS studies indicated that the end functionality was almost quantitative. Nevertheless, the termination of the lithium salt of living anionic poly(DEA) with $\mathbf{T}$ was accompanied by side reactions, leading to low functionalities of its end. The addition of $\mathrm{Ph}_{2} \mathrm{CHK}$ to the methacrylamide residue of the end-functionalized poly(DEA) converted the end of poly(DEA) to an active initiator that promote post polymerization. It is noteworthy that the reaction of $\mathrm{Ph}_{2} \mathrm{CHK}$ with a $\mathrm{N}, \mathrm{N}$-dialkylmethacrylamide resulted in only formation of a monoadduct product. A $N, N$-dialkylmethacrylamide was used for end-functionalization of polymers, and we expect this method to be useful for the preparation of star-branched polymers with well-defined structures.

Acknowledgment. This work was supported by the Grant-in-Aid for Scientific Research (No. 14750689) from the Ministry of Education, Culture, Sports, Science and Technology of Japan.

\section{REFERENCES AND NOTES}

1. “Anionic Polymerization. Principles and Practical Applications,” H. L. Hsieh, R. P. Quirk, Ed, Marcel Dekker, Inc., N.Y., Basel, Hong Kong., 1996, pp 133-135.

2. A. G. Evans and D. B. George, J. Chem. Soc., 4653 (1961).

3. A. G. Evans and D. B. George, J. Chem. Soc., 141 (1962).

4. B. C. Anderson, G. D. Andres, P. Arthur, Jr., H. W. Jacobson, L. R. Melby, A. J. Playtis, and W. H. Sharkey, Macromolecules, 14, 1599 (1981).

5. “Anionic Polymerization. Principles and Practical Applications," H. L. Hsieh, R. P. Quirk, Ed, Marcel Dekker, Inc., N.Y., Basel, Hong Kong., 1996, pp 279-291 and pp 353365.

6. A. Hirao, M. Hayashi, and N. Haraguchi, Macromol. Rapid 
Commun., 21, 1171 (2000).

7. X. Xie and T. E. Hogen-Esch, Macromolecules, 29, 1746 (1996).

8. T. Kodaita, H. Tanahashi, and K. Hara, Polym. J., 22, 649 (1990).

9. Y. Okamoto and H. Yuki, J. Polym. Sci., Polym. Chem. Ed., 19, 2647 (1981).

10. D. Xie, S. Tomczak, and T. E. Hogen-Esch, J. Polym. Sci., Part A: Polym. Chem., 39, 1403 (2001).

11. M. Kobayashi, S. Okuyama, T. Ishizone, and S. Nakahama, Macromolecules, 32, 6466 (1999).

12. M. Kobayashi, T. Ishizone, and S. Nakahama, Macromolecules, 33, 4411 (2000).

13. T. Ishizone, A. Hirao, and S. Nakahama, Macromolecules, 24, 625 (1991).

14. A. Hirao, K. Takenaka, S. Packirisamy, K. Yamaguchi, and S. Nakahama, Makromol. Chem., 186, 1157 (1985).
15. D. L. Tuleen and B. A. Hess Jr., J. Chem. Educ., 48, 476 (1971).

16. (a) R. P. Woodbery and M. W. Rathke, J. Org. Chem., 42, 1688 (1977).

(b) R. P. Woodbery and M. W. Rathke, J. Org. Chem., 43, 881 (1978).

17. D. Xie, S. Tomczak, and T. E. Hogen-Esch, J. Polym. Sci., Part A: Polym. Chem., 39, 1403 (2001).

18. B. I. Nakhmanovich, T. N. Prudskova, A. A. A-Yakubovich, and A. H. E. Müller, Macromol. Rapid Commun., 22, 1243 (2001).

19. Our private data. The end-functionalities of poly(DEA) obtained by reactions of the living polymer with a $(2,2-$ dimethyl-1,3-dioxolane-4-yl)methyl tosylate, 4-iodomethyl2,2-dimethyl-1,3-dioxolane, $N$-(2-methoxycarbonylethyl)$\mathrm{N}$-propylmethacrylamide, and ethylene oxide were $23 \%$, $36 \%, 25 \%$, and $3 \%$, respectively. 